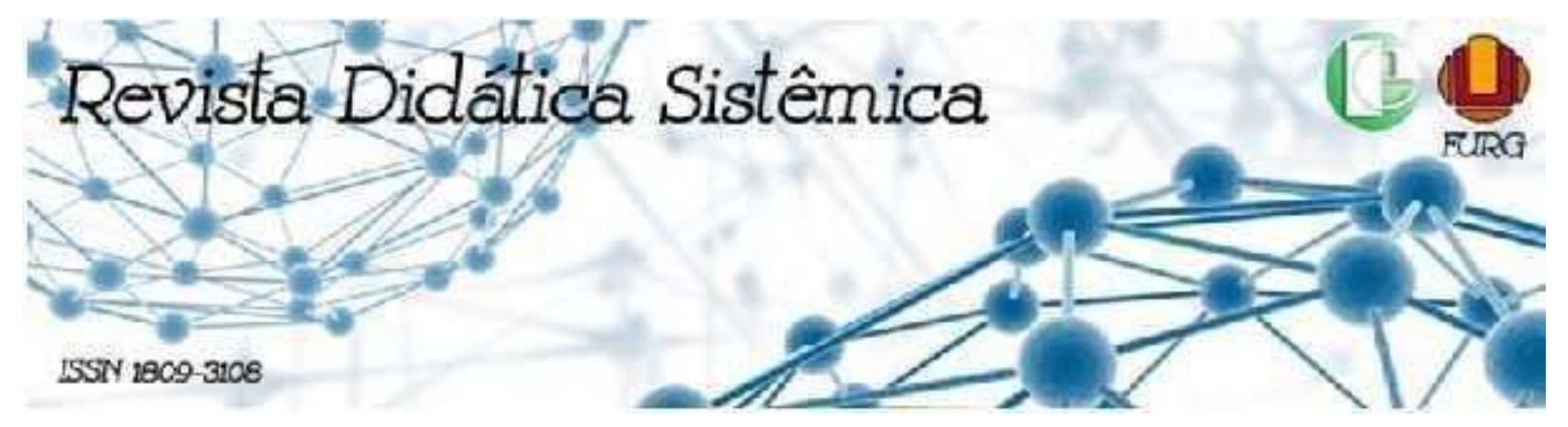

\title{
EDUCAÇÃO INFANTIL EM ESCOLAS DE ENSINO FUNDAMENTAL: HÁ ESPAÇO PARA BRINCAR E “SE-MOVIMENTAR”?
}

\author{
Heloisa Elesbão ${ }^{1}$ \\ Natália de Borba Nunes ${ }^{2}$ \\ Maria Cecília da Silva Camargo ${ }^{3}$
}

\section{RESUMO}

O corpo e o movimento são reconhecidos como potentes manifestações expressivas das crianças, dentre outras possíveis. É por meio da linguagem corporal e do movimento que as crianças constituem suas identidades e estabelecem relações com seus pares e adultos, sobretudo, nas brincadeiras, contribuindo no que a literatura classifica como culturas infantis. Considerando a relevância do binômio corpo/movimento e a centralidade do brincar na Educação Infantil (EI), o presente artigo tem por objetivo identificar o lugar destinado pelas professoras ao brincar e ao "se-movimentar" no cotidiano de turmas desta etapa de ensino, em escolas de Ensino Fundamental, na Região Central do Rio Grande do Sul. As narrativas docentes evidenciaram que as professoras têm perspectivas distintas sobre a importância do brincar e do "se-movimentar" no cotidiano da EI, ora reconhecendo o corpo e o movimento como linguagem infantil, ora reduzindo o binômio como instrumento para o desenvolvimento de outras habilidades.

Palavras-chave: Educação Infantil; Corpo/Movimento; Brincar; Se-movimentar.

\section{EARLY CHILDHOOD EDUCATION IN FUNDAMENTAL SCHOOLS: IS THERE SPACE TO PLAY AND “SELF-MOVE”?}

\begin{abstract}
The body and the movement are recognized as potent expressive manifestation sof children, among other possible ones. It is through body language and movement that children establish their identities and establish relationships with their peers and adults, especially in games, contributing to what the literature classifies as children's cultures. Considering the relevance of the binomial body/movement and the centrality of playing in Early Childhood Education (EI), this article aims to identify the place intended by the teachers to play and "move" in the daily lives of classes at this stage of teaching, in Elementary Schools in the Central Region of Rio Grande do Sul. The teachers' narratives showed that

\footnotetext{
${ }^{1}$ Doutoranda em Educação pelo Programa de Pós-Graduação em Educação da Universidade Federal de Santa Maria. Professora de Educação Física na prefeitura de Candelária, Novo Cabrais, RS - Brasil. E-mail: elesbaoheloisa@gmail.com.

${ }^{2}$ Mestranda em Educação Física pelo Programa de Pós-Graduação em Educação Física da Universidade Federal de Santa Maria. E-mail: natalianunes96@gmail.com.

${ }^{3}$ Doutora em Ciências do Movimento Humano pelo Programa de Pós-Graduação em Ciências do Movimento Humano da Universidade Federal do Rio Grande do Sul. Professora adjunta na Universidade Federal de Santa Maria, RS - Brasil. E-mail: mceciliacg6@hotmail.com.
} 
the teachers have different perspectives on the importance of playing and "moving" in the daily life of EI, sometimes recognizing the body and movement as a child's language, sometimes reducing the binomial as an instrument for the development of other skills.

Keywords: Early Childhood Education; Body/Movement; Play; Self-moving.

\section{LA EDUCACIÓN INFANTIL EN LAS ESCUELAS FUNDAMENTALES: ¿HAY ESPACIO PARA JUGAR Y "MOVERSE”?}

\section{RESUMEN}

El cuerpo y el movimento son reconocidos como potentes manifestaciones expresivas de los niños, entre otras posibles. Es a través del lenguaje corporal y el movimiento que los niños forman sus identidades y establecen relaciones con sus compañeros y adultos, especialmente em los juegos, contribuyendo a lo que la literatura clasifica como culturas infantiles. Considerando la relevância del binomio cuerpo/movimiento y la centralidade del juego em laEducación Infantil (EI), este artículo tiene como objetivo presentar el lugar que los docentes leasignan al jugar y moverse em la vida diaria de las clases en esta etapa de la enseñanza em las escuelas primarias de laregión central de Rio Grande do Sul. Las narrativas didácticas mostraron que los docentes tienen diferentes perspectivas sobre la importância del juego y el movimento em la vida diaria de la EI, reconociendo a veces el cuerpo y el movimiento como lenguaje de los niños, a veces reduciendo el binomio como instrumento para el desarrollo de otras habilidades.

Palabras-clave:Educación Infantil; Movimiento/cuerpo; Jugar; Moverse.

\section{CONSIDERAÇÕES INTRODUTÓRIAS}

A Lei 12.796, de quatro de abril de 2013, estabelece a obrigatoriedade da educação a partir de quatro anos, o que resultou na necessidade do aumento de oferta de turmas de Educação Infantil (EI) (BRASIL, 1996). A abertura de turmas de EI, junto às escolas de Ensino Fundamental, em sua maioria, visa contemplar as matrículas decorrentes dessa nova demanda (ARELARO; JACOMINI; KLEIN, 2011). Convém lembrar que no contexto no qual foi feita essa investigação, a oferta de turmas de EI em escolas de Ensino Fundamental já ocorria mesmo antes de sua obrigatoriedade, por uma demanda da própria comunidade.

De outra parte, a obrigatoriedade da Educação Física (EF) na Educação Básica, prevista por lei ${ }^{4}$, não impõe a presença de professor(a) especialista de EF, na EI, considerando-se que essa etapa da educação não se organiza por componentes curriculares, ficando tal decisão a critério da esfera municipal e, eventualmente, estadual, ao definir o quadro de docentes das respectivas redes de ensino. A realidade de muitos estados, como é o caso do Rio Grande do Sul, não assegura a presença de professor de EF no cotidiano da EI (D’AVILA; SILVA, 2018),

\footnotetext{
${ }^{4}$ A partir da redação dada pela Lei $n^{\circ} 10.793$, de $1^{\circ} .12 .2003$.
} 
ficando as atividades que envolvem o corpo/movimento e os jogos e brincadeira sob encargo das professoras regentes, em ampla maioria, pedagogas.

O ato de brincar e "Se-movimentar", conforme Kunz e Costa (2015), para as crianças, é natural e espontâneo, que logo se torna uma ação cultural e social. Por sua vez, conforme os autores, o brincar pode apresentar-se de duas formas, espontâneo ou didático. Sendo que a maioria das produções acerca da EF na EI está debruçada em estudar o brincar didatizado, preocupado com o futuro, ou seja, com o que a criança irá se tornar.

Kunz e Costa (2013, p. 52) propõem o "brincar e se-movimentar" como via para se compreender o "ser criança" e seu "envolvimento corporal com o mundo, com os outros e consigo mesma". Consideramos que existem aproximações possíveis entre o cotidiano da EI e a compreensão da importância do binômio corpo/movimento para as crianças a essa abordagem, na qual “[...] a criança que se movimenta não é mera apresentadora de movimentos criados e ofertados pelos adultos, mas autora, constituidora de sentidos e significados no seu 'SeMovimentar"” (KUNZ; COSTA, 2015, p. 18).

Conceber a criança como autora e produtora de sentidos corresponde à noção de protagonismo infantil (SARMENTO, 2008), e reconhecê-lo demanda que tenhamos uma escuta atenta e sensível às crianças. Nessa direção, faz-se necessário reconhecer a importância do movimento como forma de linguagem infantil, pelo qual as crianças podem expressar-se, desenvolver-se, estabelecer relações e construir seus conhecimentos (MOURA; COSTA; ANTUNES, 2016).

Corpo e o movimento constituem, portanto, uma importante forma de garantir que as crianças possam interagir com seus pares e com o meio, produzindo, assim, suas culturas infantis. Para isso, faz-se necessária a adoção de práticas pedagógicas no cotidiano da EI que possibilitem às crianças momentos para criarem, se expressarem e construírem seus saberes (BASEI, 2008).

A partir disso, o presente $\operatorname{artigo~}^{6}$ tem por objetivo identificar o lugar destinado ao brincar e "Se-movimentar" no cotidiano de turmas de EI, inseridas em escolas de Ensino Fundamental de um município da Região Central do Rio Grande do Sul.

\footnotetext{
${ }^{5}$ Os autores fazem uso de um conceito que se forja a partir da concepção teórico-filosófica do Movimento Humano, denominada, por Elenor Kunz, como "Se-Movimentar", fortemente influenciada pela filosofia fenomenológica (KUNZ; COSTA, 2013).

${ }^{6}$ Este texto é parte de uma dissertação de mestrado apresentada ao Programa de Pós-Graduação em Educação Física do Centro de Educação Física e Desportos da Universidade Federal de Santa Maria (CEFD/UFSM), tendo sida aprovada pelo Comitê de Ética e Pesquisa (Parecer 3.470.458), com o Certificado de Apresentação para Apreciação Ética (CAAE) 16345619.6.0000.5346.
} 


\section{CAMINHO METODOLÓGICO}

O caminho metodológico seguido no presente estudo foi a pesquisa narrativa (CONNELLY; CLANDININ, 1995), realizada em um município da Região Central do Rio Grande do Sul, em duas escolas de Ensino Fundamental, que contavam com turmas de EI (Pré A e B). Participaram do estudo 10 membros da equipe pedagógica (professoras de EI, supervisora, diretora, vice-diretora).

Foram utilizadas, neste artigo, as narrativas produzidas por meio de um questionário (GIL, 2009) com perguntas abertas relacionadas à temática da pesquisa. A análise dos dados é de inspiração bakhtiniana (BAKHTIN, 2003, 2014), considerando-se a pesquisa em sua integralidade, na qual a compreensão se fez pelo diálogo e pelo exercício da alteridade. $\mathrm{O}$ recorte da investigação, ora apresentado, traz, em si, uma análise ancorada na totalidade do processo.

A produção de narrativas caracteriza um investimento no potencial formativo a partir de um pensar e expressar-se sobre suas próprias experiências cotidianas com as crianças em relação a corpo/movimento na EI.

\section{O CORPO/MOVIMENTO COMO POSSIBILIDADE PARA SE PENSAR O BRINCAR E O SE-MOVIMENTAR NA EDUCAÇÃO INFANTIL}

Convergimos com a assertiva de que "[...] a dimensão corporal tem centralidade nas relações e interações sociais das crianças, para as quais o corpo se torna meio de exercer ação social, ou seja, é fonte de ação social" (BUSS-SIMÃO, 2014, p. 103). Por outro lado, a Base Nacional Comum Curricular (BNCC) (BRASIL, 2018) reafirma as interações e brincadeiras como eixos estruturantes da prática pedagógica na EI, já estabelecidas nas Diretrizes Curriculares Nacionais para a Educação Infantil (DCNEI) (BRASIL, 2010). Ao brincar, a criança se expressa, explora, se apropria do mundo e estabelece múltiplas interações essencialmente por meio do corpo e do movimento, o que nos levou a aproximação com o "brincar e se-movimentar".

O movimento corporal, conforme já mencionado, é considerado, principalmente na EI, uma das formas com as quais as crianças se comunicam, ou seja, um meio de interagirem com seus pares, adultos e o mundo (MOURA; COSTA; ANTUNES, 2016; SOARES, PRODÓCIMO; MARCO, 2016). Conforme a professora Lelê, o corpo/movimento, "muitas 
vezes é utilizado como linguagem, importante para o aprendizado infantil, estimulante" (QUESTIONÁRIO LELÊ). Nesse sentido, o relato da professora se aproxima do conceito de "brincar didático", apresentado por Kunz e Costa (2015, p. 14), em que o corpo/movimento é considerado recurso ou meio para atingir algum objetivo, não somente como uma possibilidade de experiência rica em si mesma.

Por sua vez, a professora Luiza expressa a necessidade das crianças se movimentarem, pois o corpo e o movimento estão "em todos os momentos, criança é movimento, é alegria. Não podemos pensar em crianças estáticas na Educação Infantil” (QUESTIONÁRIO LUIZA). A centralidade do binômio corpo/movimento, na EI, percebida pela professora Luiza, indica a pertinência de uma compreensão mais profunda sobre o engajamento corporal da criança com o mundo (KUNZ, COSTA, 2013) e sua necessidade inerente de movimentar-se.

A narrativa da professora Cassi remete ao desenvolvimento de capacidades e habilidades ao afirmar que "[...] o corpo na Educação Infantil é o principal instrumento e os movimentos e sua evolução os objetivos. Pois, nesse período, estão em pleno desenvolvimento e capacidade de mobilidade" e prossegue identificando corpo/movimento (QUESTIONÁRIO CASSI) “[...] na grande maioria dos 'conteúdos propostos' os quais precisam ser proporcionados através do trabalho diário para que os pequenos construam e aperfeiçoem o desempenho motor que vai auxiliar e facilitar na vida adulta" (QUESTIONÁRIO CASSI). Encontramos, em sua narrativa, um argumento que expressa uma perspectiva mais instrumental e que perspectiva o futuro. O brincar, nessa perspectiva, adquire um papel funcional, projetado para aquisições que sejam preparatórias para outras aprendizagens, excluindo qualquer relação com o "se-movimentar", já citado.

Para Charlote, o movimento parece permear todas as experiências das crianças na EI, pois, de acordo com sua narrativa, ele “[...] está presente em todos os momentos, é impossível pensar em Educação sem ter conhecimento sobre corpo e movimento, sendo este binômio um dos principais e fundamentais a serem trabalhados e desenvolvidos nesta etapa da Educação" e afirma perceber “[...] que corpo/movimento está ganhando mais força no currículo, principalmente com as mudanças que estão acontecendo na BNCC, mostrando a importância de se trabalhar o desenvolvimento e conhecimento tanto do corpo quanto de suas possibilidades" (QUESTIONÁRIO CHARLOTE). Embora a narrativa da professora Charlote também sugira a centralidade do corpo e do movimento junto à EI, nos perguntamos sobre o que significa "serem trabalhados e desenvolvidos"? É um questionamento que pode nos levar a múltiplas possibilidades, pois o corpo pode ser compreendido como um instrumento a ser 
utilizado, buscando atingir "objetivos" e "níveis de desenvolvimento", semelhante aos relatos das professoras Lelê e Cassi. De certo modo, sua manifestação sugere que um agente externo, no caso, a professora, exerça uma ação sobre as crianças de modo a "trabalhar e desenvolver" o corpo e o movimento com elas.

Sayão (2002) e Cancian e Goelzer (2016) discutem a preocupação, bastante presente na EI, em pedagogizar as ações infantis e dar-lhes um direcionamento produtivo. Essa necessidade diretiva pode cercear possibilidades de criações e experimentações no tempo presente que sejam protagonizadas pelas crianças em nome de objetivos estabelecidos por adultos para a aquisição de habilidades futuras. Conforme Staviski e Kunz (2017), a brincadeira vista, unicamente sob a ótica do alcance de competências, reduz a possibilidade do brincar espontâneo e livre vivido pelas crianças sem essa preocupação. Elas agem pela necessidade que sentem de brincar e de se movimentar, e por ser uma forma de interpretarem e interferirem no mundo. Tal situação expressa o que Sayão (2002, p. 58) denomina como "descompasso" entre o que as crianças desejam e o que nós, adultos, temos como intenção ao propor momentos para as interações e para as brincadeiras.

A centralidade do corpo e do movimento na EI é citada por Moni. Segundo ela, ambos estão presentes "nas atividades diárias e em diferentes espaços da escola, pois o movimento é primordial para o desenvolvimento do corpo e da mente na Educação Infantil" (QUESTIONÁRIO MONI). Parece-nos que Moni atribui grande importância ao movimento na EI, mas, ao mesmo tempo, expressa uma perspectiva fragmentada de corpo, visto de maneira dicotômica em relação à mente. Ao destacar a importância do "desenvolvimento do corpo e da mente na Educação Infantil" reafirma uma divisão que, muitas vezes, se estabelece na rotina, levando a uma fragmentação das atividades que corresponde a esse olhar e que, no conjunto, visam ao "desenvolvimento cognitivo, motor e social", também presente em sua narrativa.

As narrativas de Malu, Flora e Daia têm em comum a condição de gestoras e uma forma distinta de viverem o cotidiano da EI. Ao discorrerem sobre como o binômio corpo/movimento presente na escola, há uma convergência em relação ao destaque dado a atividades de caráter prático e, uma única vez, à referência feita à Educação Física, especificamente: "através das brincadeiras, das corridas, da Educação Física, atividades na pracinha e no pátio da escola" (QUESTIONÁRIO FLORA); "sim, em todas as atividades práticas realizadas em sala de aula" (QUESTIONÁRIO DAIA). Malu, no entanto, expressa uma perspectiva mais ampla e genérica ao relatar que "o corpo na Educação Infantil é o que está em evidência no desenvolvimento da criança" (QUESTIONÁRIO PROFESSORA MALU, 
CORPO E MOVIMENTO), sem aprofundar qualquer aspecto relacionado a brincar.

Quando refletimos sobre corpo e movimento, muitas são as possibilidades de estabelecer relações com a EI, seja em atividades mais gerais, considerando o corpo e o movimento linguagem corporal, seja em atividades que tenham como objetivo o movimento corporal e/ou o desenvolvimento de habilidades

Para a professora Taci, o corpo e o movimento perpassam a EI "através das expressões do corpo, artísticas e musicais, e das relações entre as crianças (brincadeiras de faz de conta)" e "através de atividades e conteúdos propostos" (QUESTIONÁRIO TACI). E, para Bel, o corpo e o movimento estão presentes na sala de aula, especificamente, nos momentos destinados à brincadeira, ou, então, nos momentos disponibilizados para a realização de atividades em que o movimento seja central em seu processo, que poderão ser realizadas em outros espaços/tempos da escola. Conforme essa professora, o movimento está “[...] em vários momentos, tanto dentro da sala nas brincadeiras, como também em momentos de atividades físicas em outros espaços na escola" (QUESTIONÁRIO BEL). Sob essa perspectiva, há a presença do corpo e do movimento em espaços e tempos destinados às brincadeiras, como possibilidade de expressão e interação entre as crianças, como menciona Taci, mas parecendo desconsiderar sua potência nas experiências infantis.

Chamou nossa atenção a forma como algumas professoras relacionam o corpo e o movimento a um caráter instrumental, muito próximo ao encontrado no Referencial Curricular Nacional para a Educação Infantil (RCNEI) (BRASIL, 1998). Conforme Mello et al. (2016), essa maneira instrumental de perceber o corpo tem como objetivo principal o apoio a futuras aprendizagens, atribuindo grande importância ao desenvolvimento psicomotor. Nesse caso, as experiências corporais e de movimento não são o foco principal do trabalho junto a EI, mas um meio que pode levar a outras aquisições.

O currículo embasa as ações que serão realizadas dentro do ambiente escolar, o modo com que o trabalho pedagógico se efetivará, as formas de organização do espaço/tempo, os procedimentos e organizações didáticas, normas, técnicas e valores, não sendo, portanto, neutro, pois, nele, está expressa uma cultura (PINHEIRO, 2002; VEIGA, 2004). Diante disso, possivelmente, a forma com que o corpo/movimento aparecerá no currículo infantil da escola terá ligação com a cultura escolar, com a importância atribuída aos mesmos e à forma com que são reconhecidos nesse processo, além de sofrerem influência dos documentos normativos existentes, dentre os quais, podemos citar as DCNEI (BRASIL, 2010), BNCC (BRASIL, 2018) e o Referencial Curricular Gaúcho (RCG) (RIO GRANDE DO SUL, 2018). 
As professoras, ao estabelecerem uma relação entre o corpo/movimento e o currículo infantil, demonstraram diferentes visões acerca de sua relação/constituição, e estabeleceram distintos significados a ambos. Algumas narrativas, como no caso da professora Luiza, atribuem centralidade ao corpo e ao movimento na EI. Para ela, há indissociabilidade entre o currículo e o corpo/movimento, sendo esse binômio imprescindível no trabalho pedagógico com a EI. Nas suas palavras: "em todas as atividades propostas o movimento e a interação estão presentes. Um currículo que não abrange atividades que incentivem ou trabalhem o corpo não pode ser realizado para crianças" (QUESTIONÁRIO LUIZA). Assim, de forma recorrente, essa professora manifestou um entendimento da necessidade do brincar vinculado ao corpo e ao movimento como um fim em si mesmo.

Conforme Barbosa, Martins e Mello (2019), ao considerar as experiências vividas pelas crianças e proporcionar-lhes outras, nos processos educativos na escola, é importante nos atentarmos às dimensões expressivas, corporais, sensoriais, de movimento e do cuidado, indicadoras de uma educação que leve em conta os significados construídos pelas crianças e seus desafios enfrentados em variados ambientes, podendo, com isso, considerar suas variadas especificidades.

Ao cogitarmos os Campos de Experiência dentro de uma proposta de organização curricular para a EI, faz-se necessário que a aprendizagem seja direcionada às crianças, aos contextos em que estão inseridas e a suas experiências (BARBOSA; MARTINS; MELLO, 2019). Por sua vez, o Campo de Experiência “Corpo, gestos e movimentos" contém direitos de aprendizagem e de desenvolvimento que possibilitam visão e importância ao corpo/movimento de maneira relacionada às oportunidades de produção de uma cultura infantil pelas crianças (MELLO et al., 2016). E, ao mesmo tempo, em sua versão final (BRASIL, 2018), apresentam objetivos de aprendizagem que podem induzir a uma concepção de corpo e movimento de caráter mais instrumental e fragmentado, a partir de um modelo prescritivo voltado a habilidades a serem atingidas, conforme apontado por Barbosa, Martins e Mello (2019).

Para Kunz e Costa (2015), as crianças tendem, de maneira natural, a se movimentarem, expressando-se por meio do movimento, possibilitando que elas dialoguem e questionem a realidade em que vivem, de modo a estabelecer aspectos relacionados à criatividade e à autonomia. Nesse sentido, compreendemos que a presença do corpo/movimento, dentro de um currículo infantil, é inerente à própria infância, ou seja, impossível se organizar um currículo que não leve em conta o corpo e o movimento, considerando sua centralidade no trabalho junto à EI e à necessidade das crianças em se movimentarem. 


\section{CONSIDERAÇÕES FINAIS}

Reiteramos que este texto representa um recorte de um estudo mais amplo que abarcou corpo/movimento na dinâmica curricular na Educação Infantil. As considerações, aqui apresentadas, resultam de um processo de análise a partir do qual buscamos identificar o lugar destinado pelas professoras ao brincar e ao "se-movimentar" no cotidiano de turmas, nas narrativas produzidas pelas professoras de turmas de EI, inseridas em escolas de Ensino Fundamental, de um município da Região Central do Rio Grande do Sul. A aproximação com o brincar e "se-movimentar" se tornou possível a partir de um entendimento de que a criança vive e apreende o mundo pelo brincar e o faz, essencialmente, por meio do corpo e do movimento.

Compreendemos ser necessário considerar o "nosso lugar de fala", ou seja, a nossa visão a partir da perspectiva de professoras de EF, a qual se distingue da perspectiva das professoras colaboradoras do estudo. No decorrer das análises, buscamos manter uma vigilância no sentido de não termos um discurso corporativo, uma vez que nossa intenção era fomentar o debate sobre corpo e movimento na EI e sobre as concepções de infância que perpassam essa etapa da educação.

O corpo e o movimento são centrais nas narrativas das professoras. No entanto, encontramos uma diversidade nos sentidos por ela atribuídos. Algumas professoras associam o corpo e o movimento a um caráter meramente instrumental, ou seja, como um meio para o desenvolvimento de outras habilidades. Outras professoras, todavia, vinculam o corpo/movimento à realização de experiências importantes na EI, como também a uma importante forma de comunicação das crianças. Tais manifestações, no entanto, foram minoritárias.

Nesse sentido, o lugar destinado ao brincar e ao "Se-movimentar" varia, incluindo professoras que associam o brincar ao que Kunz e Costa (2015, p. 14) chamam de "brincar didático". Nesse caso, os interesses e as experiências das crianças não são considerados ou são relegados a um segundo plano, prevalecendo objetivos e interesses do mundo adulto a serem cumpridos. Por outro lado, a visão de que as crianças têm uma incessante necessidade de se movimentar emergiu nas narrativas, nos sugerindo um espaço rico de possibilidades para o brincar e o "Se-movimentar", aqui entendidos como "[...] um diálogo da criança com o mundo, com os outros e consigo mesma" e que expressa seu "[...] engajamento corporal com o mundo [...]" (KUNZ; COSTA, 2015, p. 52). 
É importante ressaltar que nos encontramos em um momento no qual muitas escolas, como é o caso das participantes da pesquisa, estão reelaborando seus projetos políticospedagógicos, alinhados com a BNCC (BRASIL, 2018) e o RCG (RIO GRANDE DO SUL, 2018). As considerações que ora apresentamos expressam uma compreensão da primeira etapa no processo de produção das narrativas que se aprofundou ao longo do processo, possibilitandonos situá-las em um movimento de reorganização do projeto pedagógico da escola.

Sinalizam, no entanto, indícios em relação aos sentidos que as professoras atribuem a corpo/movimento na EI e, do mesmo modo, algumas "pistas" sobre possíveis brechas para que o brincar e "se-movimentar" possa encontrar o seu lugar na dinâmica curricular e no cotidiano das escolas.

A necessária valorização das experiências concretas e saberes das crianças e o protagonismo infantil demandam um olhar sensível e acolhedor às manifestações da cultura infantil. Nessa direção, é preciso lembrar que o brincar da criança é uma necessidade à qual ela responde, essencialmente, por meio do movimento.

Diante disso, parece-nos pertinentes discussões que tenham lugar para o brincar e o "Semovimentar", dada a importância e o significado que ambos têm para as crianças e a sua potência no trabalho pedagógico com a EI.

\section{REFERÊNCIAS}

ARELARO, L. R; JACOMINI, M. A.; KLEIN, S. B. O Ensino Fundamental de nove anos e o direito à educação. Educação e Pesquisa, São Paulo, v. 37, n. 1, p. 35-51, jan./abr. 2011. Disponível em: $<$ https://www.scielo.br/pdf/ep/v37n1/v37n1a03.pdf > Acesso em: 18 nov. 2020.

BAKHTIN, M. Estética da criação verbal. São Paulo: Martins Fontes, 2003. 4. ed. Tradução de Paulo Bezerra.

BAKHTIN, M. Marxismo e filosofia da linguagem. São Paulo: Hucitec, 2014. 16. ed. Tradução de Michel Lahud e Carlos Henrique D. Chagas Cruz.

BARBOSA, R. F. M.; MARTINS, R. L. D. R.; MELLO, A. da. S. A educação infantil na base nacional comum curricular: avanços e retrocessos. Movimento-Revista de Educação, Niterói, v. 6, n. 10, p. 147-172, jan./jun. 2019. Disponível em:

<https://periodicos.uff.br/revistamovimento/article/view/32667> Acesso em: 15 ago. 2019.

BASEI, A. P. A educação física na educação infantil: a importância do movimentar-se e suas contribuições no desenvolvimento da criança. Revista Iberoamericana de Educación, Madrid, v. 3, n. 47, p. 1-12, out. 2008. Disponível em: 〈https://dialnet.unirioja.es/servlet/articulo?codigo=2730353 > Acesso em: 08 jun. 2018.

BRASIL. Ministério da Educação e do Desporto. Referencial Curricular Nacional para a Educação Infantil. Brasília: MEC/SEF, 1998. v. 1. Disponível em:

<http://portal.mec.gov.br/seb/arquivos/pdf/rcnei_vol1.pdf $>$ Acesso em: 17 jun. 2019.

BRASIL. Ministério da Educação. Secretaria de Educação Básica. Base Nacional Comum 
Curricular. Brasília: MEC/SEB, 2018. Disponível em:

$\langle$ http://basenacionalcomum.mec.gov.br/images/BNCC_EI_EF_110518_versaofinal_site.pdf $>$ Acesso em: 08 jun. 2019.

BRASIL. Lei de Diretrizes e Bases da Educação Nacional. Lei no 9394, de20 de dezembro de 1996. Estabelece asdiretrizes e bases da educação nacional. Brasília, DF, 1996. Disponível em: <http://www.planalto.gov.br/ccivil 03/leis/19394.htm> Acesso em: 08 mar. 2021.

BRASIL. Ministério da Educação. Secretaria de Educação Básica. Diretrizes Curriculares Nacionais para a Educação Infantil. Brasília: MEC/SEB, 2010. Disponível em:

$<$ http://portal.mec.gov.br/index.php?option=com docman\&view=download\&alias=9769-

diretrizescurriculares-2012\&category_slug=janeiro-2012-pdf\&Itemid=30192> Acesso em: 29 jul.

2020.

BUSS-SIMÃO, M. Relações sociais na educação infantil: olhar sobre o corpo e os sentimentos.

Educação, Porto Alegre, v. 37, n. 1, p. 101-109, jan./abr. 2014. Disponível em:

$<$ https://revistaseletronicas.pucrs.br/ojs/index.php/faced/article/view/11199/10930> Acesso em: 31 ago. 2020.

CANCIAN, V. A.; GOELZER, J. Práticas pedagógicas na Educação Infantil: do lugar da impossibilidade ao lugar da possibilidade. In: CANCIAN, V. A.; GALLINA, S. F. da S.; WESCHENFELDER, N. (Org.). Pedagogias das infâncias, crianças e docências na educação infantil. 1. ed. Santa Maria: UFSM, 2016. v. 1. p. 161 - 177.

CONNELLY, F. M.; CLANDININ, D. J. Relatos de experiencia e investigación narrativa. In: LARROSA, J. et al. (Org.). Déjame que te cuente: ensayos sobre narrativa y educación. Barcelona: Editorial Laertes, 1995. p. 11-59.

D’AVILA, A. da. S.; SILVA, L. O. e. Educação física na educação infantil: o papel do professor de educação física. Kinesis, Santa Maria, v. 36 n. 1, jan./abr. p. 44-57, 2018. Disponível em: <https://periodicos.ufsm.br/kinesis/article/view/31365/pdf > Acesso em: 20 dez. 2020.

GIL, A. C. Métodos e técnicas de pesquisa social. São Paulo: Atlas, 2009. 6. ed.

KUNZ, E.; COSTA, A. R. A imprescindível e vital necessidade da criança: "brincar e semovimentar". In: KUNZ, E. (Org.). Brincar \& se-movimentar: tempos e espaços de vida da criança. Ijuí: Unijuí, 2015. p. 13-37.

MELLO, A. da S. et al. A educação infantil na base nacional comum curricular: pressupostos e interfaces com a educação física. Motrivivência, Florianópolis, v. 28, n. 48, p. 130-149, set. 2016. Disponível em: <https://periodicos.ufsc.br/index.php/motrivivencia/article/view/21758042.2016v28n48p130/32567> Acesso em: 08 mar. 2019.

MOURA, D. L.; COSTA, K. R. N.; ANTUNES, M. M. Educação física e educação infantil: uma análise em seis periódicos nacionais. Pensar a Prática, Goiânia, v. 19, n. 1, p. 182-195, jan./mar. 2016. Disponível em: 〈https://www.revistas.ufg.br/fef/article/view/34061> Acesso em: 09 jun. 2019.

PINHEIRO, M. E. Ação coletiva como referencial para a organização do trabalho pedagógico. In: VEIGA, I. P. A. et al. (Orgs.). Escola: espaço do projeto político-pedagógico. Campinas: Papirus, 2002. 6 ed. p. 75-94.

RIO GRANDE DO SUL. Secretaria de Estado da Educação. Departamento Pedagógico, União Nacional dos Dirigentes Municipais de Educação. Referencial Curricular Gaúcho: Educação Infantil. Porto Alegre: Secretaria de Estado da Educação, Departamento Pedagógico, 2018. v. 1. Disponível em: 〈http://portal.educacao.rs.gov.br/Portals/1/Files/1532.pdf> Acesso em: 08 jun. 2019.

SARMENTO, M. J. Sociologia da infância: correntes e confluências. In: SARMENTO, M. J.; GOUVEA, M. C. S. de. (Orgs.). Estudos da infância: educação e práticas sociais. Petrópolis, RJ: Vozes, 2008. p. 17-39.

SAYÃO, D. T. Corpo e movimento: notas para problematizar algumas questões relacionadas à educação infantil e a educação física. Revista Brasileira de Ciências doEsporte, Campinas, v. 23, n. 2, p. 55-67, jan. 2002. Disponível em: 〈http://revista.cbce.org.br/index.php/RBCE/article/view/270> 
Acesso em: 15 jun. 2019.

SOARES, D. B.; PRODÓCIMO, E. MARCO, A. de. O diálogo na educação infantil: o movimento, a interdisciplinaridade e a educação física. Movimento, Porto Alegre, v. 22, n. 4, 1195-1208, out./dez. 2016. Disponível em: <https://seer.ufrgs.br/Movimento/article/view/57571/39729> Acesso em: 08 jun. 2019.

STAVISKI, G. KUNZ, E. Sem tempo de ser criança: o Se-movimentar como possibilidade de transgredir uma insensibilidade para o momento presente. In: KUNZ, E. (Org.). Brincar e semovimentar: tempos e espaços de vida da criança. 2. ed. Ijuí: Editora Unijuí, 2017. p. 39-70.

VEIGA, I. P. A. Projeto político-pedagógico da escola: uma construção coletiva. In: VEIGA, I. P. A. (Org.). Projeto político-pedagógico da escola: uma construção possível. Campinas: Papirus, 2004. 17. ed. p. 9-35. 